\title{
MECHANICAL AND IRRADIATION PROPERTIES OF ZIRCONIUM ALLOYS IRRADIATED IN HANARO
}

\author{
OH-HYUN KWON*, KYONG-BO EOM, JAE-IK KIM, JUNG-MIN SUH, and KYEONG-LAK JEON \\ KEPCO Nuclear Fuel Co. Ltd \\ 1045 Daedeok-daero, Yuseong-gu, Daejeon, 305-600, Korea \\ *Corresponding author. E-mail : ohkwon@knfc.co.kr
}

Received December 21, 2010

These experimental studies are carried out to build a database for analyzing fuel performance in nuclear power plants. In particular, this study focuses on the mechanical and irradiation properties of three kinds of zirconium alloy (Alloy A, Alloy B and Alloy C) irradiated in the HANARO (High-flux Advanced Neutron Application Reactor), one of the leading multipurpose research reactors in the world. Yield strength and ultimate tensile strength were measured to determine the mechanical properties before and after irradiation, while irradiation growth was measured for the irradiation properties. The samples for irradiation testing are classified by texture. For the irradiation condition, all samples were wrapped into the capsule (07M-13N) and irradiated in the HANARO for about 100 days $\left(\mathrm{E}>1.0 \mathrm{MeV}, 1.1 \times 10^{21} \mathrm{n} / \mathrm{cm}^{2}\right)$.

These tests and results indicate that the mechanical properties of zirconium alloys are similar whether unirradiated or irradiated. Alloy B has shown the highest yield strength and tensile strength properties compared to other alloys in irradiated condition. Even though each of the zirconium alloys has a different alloying content, this content does not seem to affect the mechanical properties under an unirradiated condition and low fluence. And all the alloys have shown the tendency to increase in yield strength and ultimate tensile strength. Transverse specimens of each of the zirconium alloys have a slightly lower irradiation growth tendency than longitudinal specimens. However, for clear analysis of texture effects, further testing under higher irradiation conditions is needed.

KEYWORDS : Irradiation Growth, Irradiation Test, Mechanical Property, HANARO, Performance

\section{INTRODUCTION}

Zirconium-based alloys are used widely for fuel cladding and other core components. Therefore, the effect of neutron irradiation of these alloys has been investigated extensively. In particular, the changes in mechanical properties are well organized [1]. Generally, under more irradiation, zirconium alloys exhibit an irradiation hardening effect [1].

Irradiation growth under fast neutron irradiation is the main source of dimensional change in zirconium alloys. This is thought to result from the partitioning of irradiationinduced interstitials and vacancies between various point defect sinks, such as dislocations, grain boundaries and solute atom traps. The metallurgical factors (texture, grain size, grain shape and dislocation density) affecting irradiation growth are well known from previous studies [2]. The effect of crystallographic texture on irradiation growth is well established and organized. The free irradiation effect with the combined crystallographic texture is also analyzed [3]. Harbottle reported the difference in growth strains of transverse and longitudinal strips found by using the equation that the axial growth is proportional to $1-3 \mathrm{f}$ (f : texture parameter) [4].

The grid strap component of a fuel assembly under irradiation in the plant is considered to be free of growth and without internal stress. In this study, free growth under irradiation in both the HANARO and the plant reactor is compared in order to analyze differences between the two results.

\section{EXPERIMENTAL}

To measure the mechanical properties, zirconium alloy specimens (Alloy A, Alloy B and Alloy C) with a length of $26 \mathrm{~mm}$ were prepared for testing. The thickness of 0.66 $\mathrm{mm}$ was used for each of the zirconium alloy specimens shown in Fig. 1. 
To measure irradiation growth, zirconium alloy specimens (Alloy A, Alloy B and Alloy C) with a length of $77 \mathrm{~mm}$ were prepared for testing. The same thickness $(0.66 \mathrm{~mm})$ was used for each of the zirconium alloy longitudinal and transverse specimens shown in Fig. 2.

These specimens were encapsulated and irradiated in the HANARO facility, a multipurpose research reactor with a world-class high neutron flux. The amount of fast neutron fluences $(\mathrm{E}>1.0 \mathrm{MeV})$ was approximately $1.1 \times 10^{21}(\mathrm{n}$ $\left./ \mathrm{cm}^{2}\right)$. The temperature $\left(300 \pm 10^{\circ} \mathrm{C}\right)$ was maintained during the irradiation test. After irradiation testing, for mechanical properties, a universal testing machine in a hot cell was used with the condition of a $0.5 \mathrm{~mm} / \mathrm{min}$ uniaxial loading rate. And the loading force was under $5 \mathrm{kN}(510 \mathrm{kgf})$. During the test, the loading force and displacement data were recorded and converted to ASCII form. After data acquisition, the stress-strain curve, elongation and strength were calculated. The universal testing machine for mechanical properties was used as an equipment system (MTS Model 810) that was installed in the hot cell as shown in Fig. 3.

To measure irradiation growth, the longitudinal length and transverse lengths of each specimen were measured

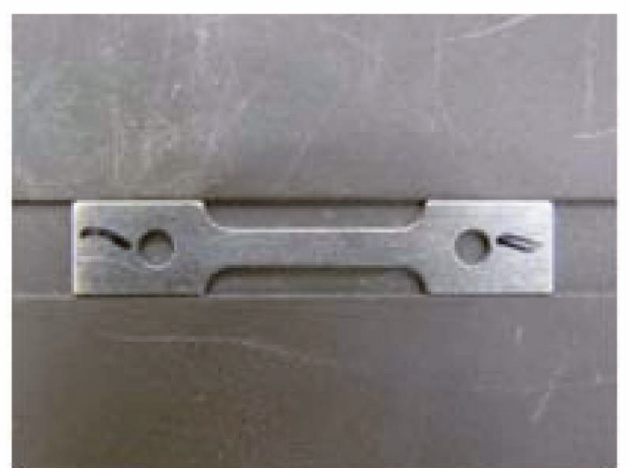

Fig. 1. Zirconium Alloy Specimens Used to Measure Mechanical Properties

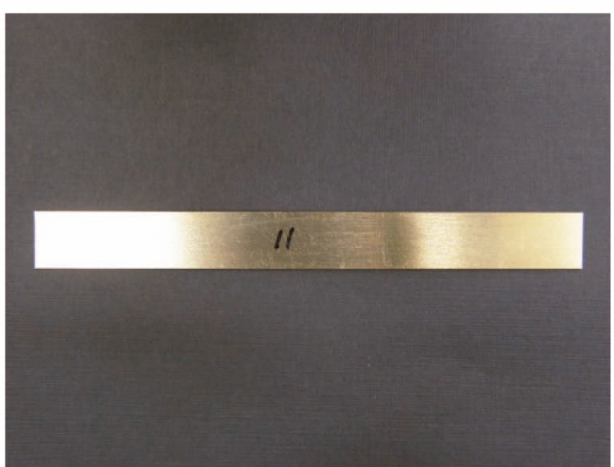

Fig. 2. Zirconium Alloy Specimens Used to Measure Irradiation Properties with a micrometer as shown in Fig. 4. The micrometer has a resolution of $0.001 \mathrm{~mm}$, which enables the dimensional differences of specimens to be measured. The dimensional changes were compared based on measurements of the specimens before and after irradiation. Additionally, the dimensional changes of the grid strap, which was irradiated in the plant, were also compared to measure free irradiation growth. The data were acquired through the results of previous studies [5].

\subsection{Capsule Design and Specimen Configuration for Irradiation in HANARO}

The structure concept of the capsule used for the specimens was based on the 05M-07U type capsule that is usually fabricated for irradiation testing; the capsule was made with the same material used to fabricate nuclear fuel components. The capsule is composed of three parts

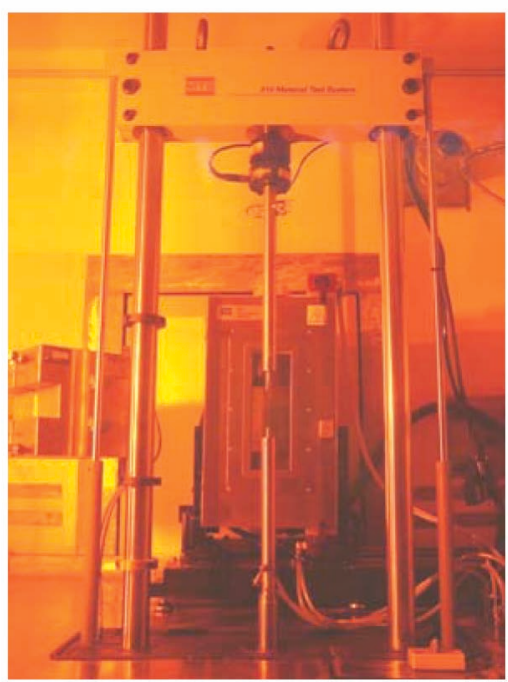

Fig. 3. Equipment System Used to Measure Mechanical Properties in a Hot Cell

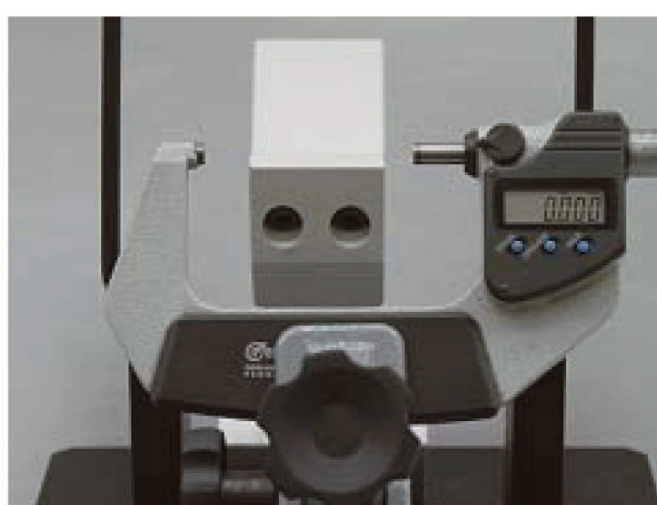

Fig. 4. Micrometer Used to Measure Irradiation Growth 
(significant main part, protection part and guide part). The T/C and F/M and instrumentation design are identical to those of the current existing capsule. One output of the temperature of the specimens was controlled by balancing the degrees of vacuum with helium inside the capsule. The reactors can operate independently and are tuned to the final target temperature with an electric heater. The $07 \mathrm{M}-13 \mathrm{~N}$ capsule used in this study was recommended for material testing of zirconium alloy, Inconel-718 and support material consisting of a $1 \times 1$ cell grid of buckling including spring specimen, tensile specimen, welded organization, strength specimen, research irradiation growth and spring characteristic specifications. The four standard tests were applied for the specimen capsule for this irradiation investigation. Basically, the five stages of the same material were placed following the conception that the same material specimens are composed in the same stage inside. However, in some locations, the specimen samples were sometimes placed by mixing different materials. The total number of specimens including specimens for the other test is 398 and the spare spaces in the capsule are filled with dummy spacer specimens made from a similar material.

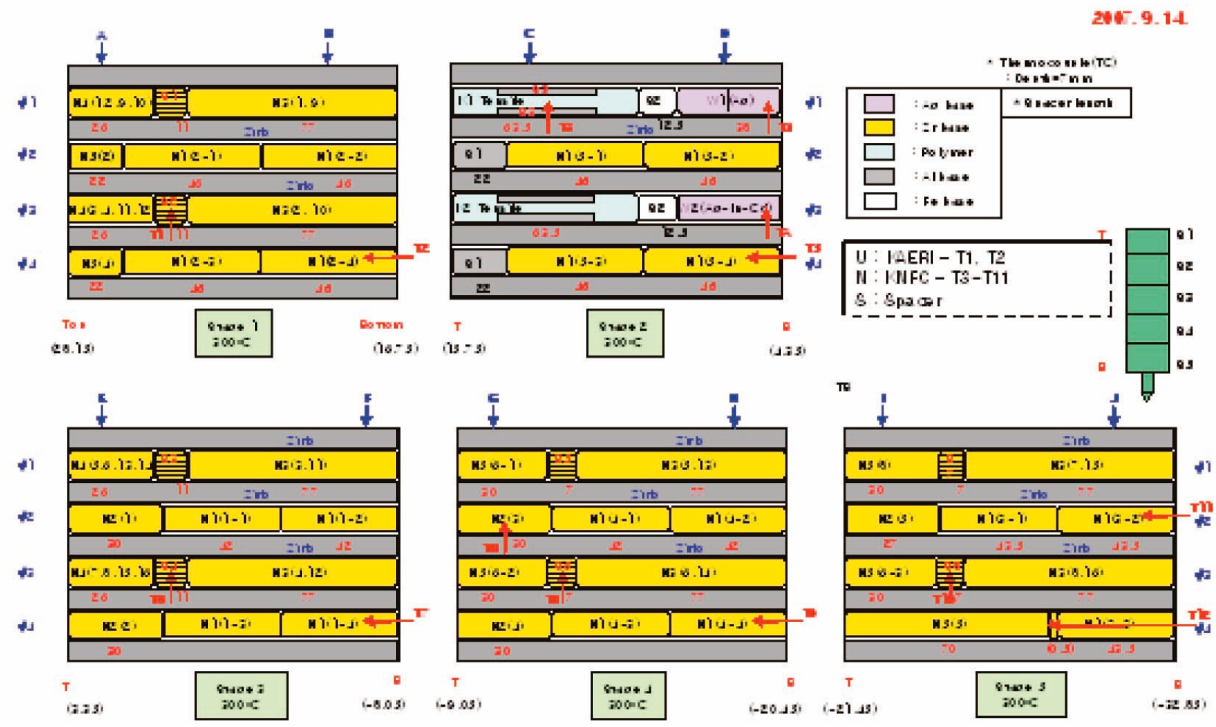

Fig. 5. Specimen Configuration of the 07M-13N Capsule Interior (Cross Section - Longitudinal)

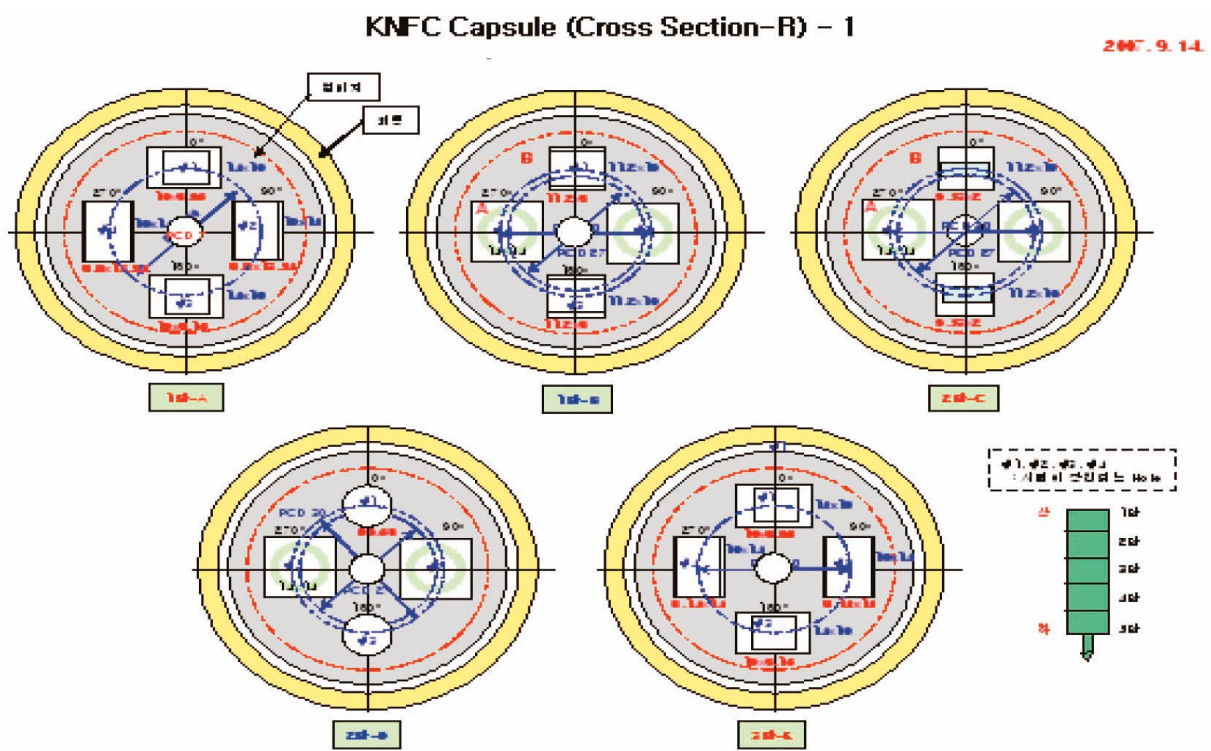

Fig. 6. Specimen Configuration of the 07M-13N Capsule Interior (Cross Section - Vertical) 


\subsection{Fluence and Temperature in HANARO}

The basic structure of the $07 \mathrm{M}-13 \mathrm{~N}$ capsule is similar to that of the $05 \mathrm{M}-07 \mathrm{U}$ capsule, which has already undergone irradiation testing. For this study, the 07M-13N capsule was under the same power (30MW) in HANARO used with the preceding experience in the case of the $05 \mathrm{M}-07 \mathrm{U}$ capsule. However, the specimens in the 07M$13 \mathrm{~N}$ capsule have such strong neutron characteristics that the nuclear characteristics design was recalculated and considered for safety and reactivity. For the temperature rating, the control rod position $(450 \mathrm{~mm})$ was considered. To design and calculate the target temperature $300^{\circ} \mathrm{C}$, the thermocouple was installed into the $07 \mathrm{M}-13 \mathrm{~N}$ capsule and the capsule was modified for symmetric geometry. To confirm the safety of the reactor, the reactivity values for various conditions under the control rod position for $450 \mathrm{~mm}$ were generated. The fast neutron flux in the reactor under irradiation examination is shown in Fig. 7. In this case, the values for thefast neutron flux, where neutron energy is morethan $0.1 \mathrm{MeV}$ and $1.0 \mathrm{MeV}$ relatively, are calculated and shown below. According to the fast neutron calculation, the maximum flux at the position slightly below the central core reached to about $3.1 \times 10^{14} \mathrm{n} / \mathrm{cm}^{2}(\mathrm{E}>0.1 \mathrm{MeV})$ and $1.5 \times 10^{14} \mathrm{n} / \mathrm{cm}^{2}(\mathrm{E}>$ $1.0 \mathrm{MeV})$. In this study, The net fluences were intended to reach $1.1 \times 10^{20} \mathrm{n} / \mathrm{cm}^{2}(\mathrm{E}>1.0 \mathrm{MeV})$ approximately by considering the flux.

\section{RESULTS}

\subsection{Mechanical Properties of Zirconium Alloys}

Previous studies have been conducted on the mechanical property changes of zirconium alloys. According to one previous study, irradiation hardening arises from the interaction of moving dislocation with a forest of irradiation-induced localized obstacles randomly distributed in the glide plane [6]. Based on the defects and clusters theory in zirconium alloys, the strength tends

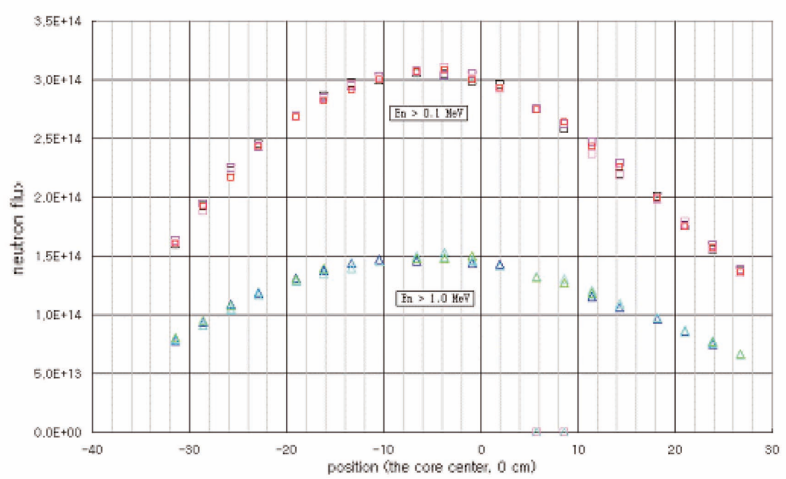

Fig. 7. Fast Flux at the Position (Control Rod Position: $450 \mathrm{~mm}$ ) to depend on fluence after low temperature irradiation. The hardening effect caused by elevated temperature irradiation showed a reduced dependence on fluence [7]. Some studies have shown that yield strength increases as the fluence increases at each temperature [8]. And with regard to the alloying element difference, the changes in yield strength for zircaloy- 2 and zircaloy- 4 are shown as a function of the square root of the fluence [7]. The differences between zircaloy- 2 and zircaloy- 4 in yield strength are within $10 \%$.

In this study, the results shown in Figs. 8 and 9 indicate that the zirconium alloys have similar average

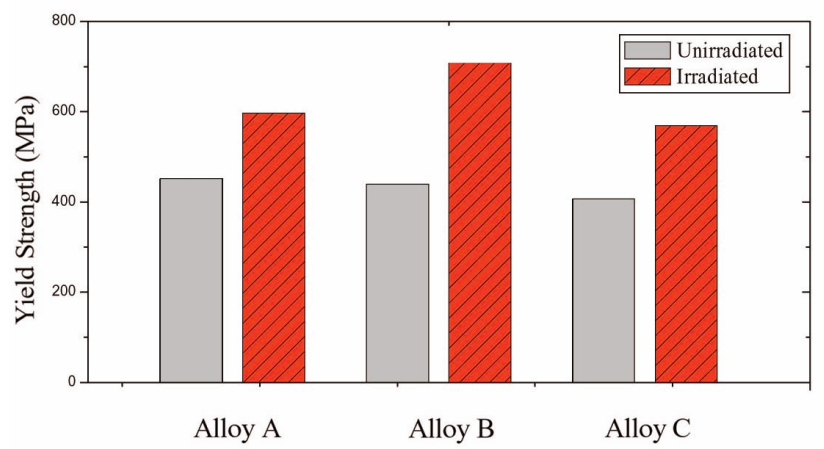

Fig. 8. Average Yield Strength for Unirradiated and Irradiated Zirconium Alloy Specimens

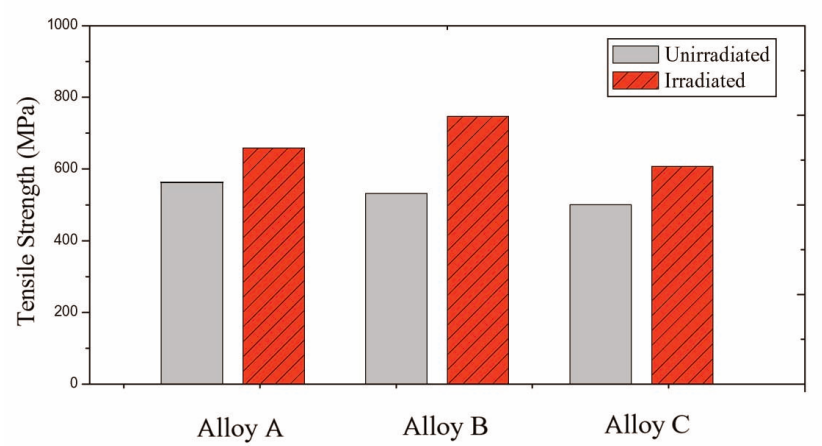

Fig. 9. Average Ultimate Tensile Strength for Unirradiated and Irradiated Zirconium Alloy Specimens

Table 1. Major and Minor Element Content of Each Alloy

\begin{tabular}{c|c|c|c}
\hline Element & Alloy A (wt\%) & Alloy B (wt\%) & Alloy C (wt\%) \\
\hline $\mathrm{Nb}$ & 1.1 & 1.0 & - \\
\hline $\mathrm{Sn}$ & - & 0.95 & 1.32 \\
\hline $\mathrm{O}$ & 0.125 & 0.120 & 0.120 \\
\hline $\mathrm{Fe}$ & 0.050 & 0.115 & 0.275 \\
\hline $\mathrm{Zr}$ & Bal. & Bal. & Bal. \\
\hline
\end{tabular}


mechanical properties, even though each of the zirconium alloys has different alloying elements. Alloy B has shown the highest yield strength and tensile strength properties compared to other alloys in irradiated condition.

Even though each of the zirconium alloys has a different alloying content, this content variation does not seem to affect the mechanical properties under an unirradiated condition and low fluence.

Alloy B has increases in yield strength and tensile strength of $61 \%$ and $41 \%$, respectively, after irradiation. And all the other alloys have shown a tendency to increase in yield strength and ultimate tensile strength.

\subsection{Irradiation Growth by Texture}

According to Harbottle's study, the texture parameter (Kearns number) has the relation of 1-3f [4]. Some studies have shown the experimental results of texture effects on growth. Rogerson's results are consistent with a 1-3f volume-conserving growth process at high temperatures [9]. And the influence of alloys appears to be quite complex. The effect on growth of some minor elements was experimentally studied and showed that some of these elements may restrict growth [10]. Likewise, the irradiation growth of all the transverse specimens shown in Fig. 10 is smaller than those of longitudinal specimens. However, the overall differences between transverse and longitudinal specimens are not comparable to the relation of the 1-3f equation when considering the textures shown in Table 2. These results seem to be due to low fluence. Therefore, for clear analysis of texture effects, further testing under higher irradiation conditions is needed.

\subsection{Irradiation Growth in the Plant Reactor}

In the plant reactor, according to Steven's study, the growth results of zirconium alloys are well documented and written in Table 3 as one of the representative growths on fluence [5]. For our analysis, the condition of irradiation is thought to be the beginning of the irradiation cycle in

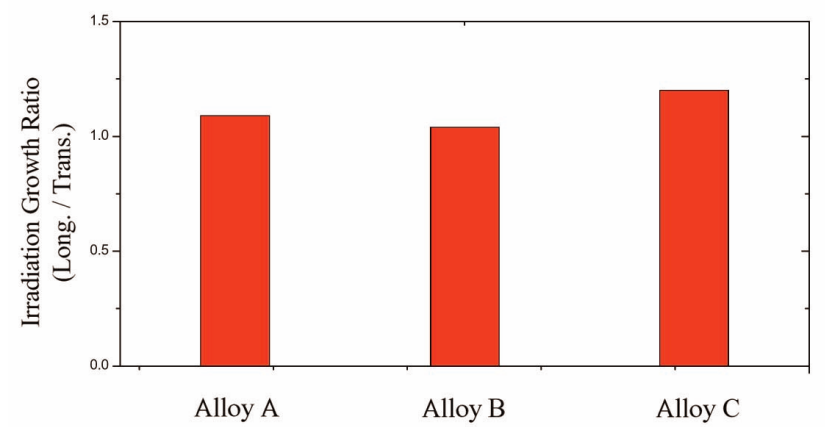

Fig. 10. Average Irradiation Growth Ratio (Longitudinal Specimen Growth (\%) / Transverse Specimen Growth (\%)) the plant. The alloy B specimen results of the irradiation tests are quite considerable in comparison with the growth of the alloy B grid strap in the plant as shown in Table 3. The test results indicate that, without any stress, the free irradiation growth could be more than we previously predicted in the plant. In addition, considerable irradiation growth in the HANARO seems to be due to measurement uncertainty caused by samples that were not long enough. For more precise analysis, more irradiation data with high fluence and longer specimens must be acquired.

\section{CONCLUSION}

These tests and results indicate that the mechanical properties of each individual zirconium alloy are similar in either unirradiated or irradiated condition. Alloy B has shown the highest yield strength and tensile strength properties compared to those of other alloys in the irradiated condition. Even though each of the zirconium alloys has a different alloying content, this content does not seem to affect the mechanical properties under an unirradiated condition and low fluence. And all the alloys have shown the tendency to increase in yield strength and ultimate tensile strength.

Transverse specimens of each of the zirconium alloys have a slightly lower irradiation growth tendency than longitudinal specimens. However, for clear analysis of texture effects, testing under higher irradiation conditions is needed.

In comparison to irradiation growth in the plant, the results of these irradiation tests are more considerable than those predicted based on plant experience. More irradiation growth in the HANARO seems to be due to

Table 2. Zirconium Alloy Texture Parameter (Kearns Number)

\begin{tabular}{c|c|c}
\hline Alloy & Longitudinal Specimen & Transverse Specimen \\
\hline Alloy A & 0.075 & 0.256 \\
\hline Alloy B & 0.066 & 0.233 \\
\hline Alloy C & 0.109 & 0.138 \\
\hline
\end{tabular}

Table 3. Comparison of Grid Strap Growth Results in the Plant and HANARO

\begin{tabular}{c|c|c|c}
\hline Alloy B Grid & Growth $(\%)$ & $\begin{array}{c}\text { Fluence } \\
\left(10^{21} \mathrm{n} / \mathrm{cm}^{2}\right)\end{array}$ & $\begin{array}{c}\text { Temperature } \\
\left({ }^{\circ} \mathrm{C}\right)\end{array}$ \\
\hline In the Plant $^{*}$ & 0.08 & 8.790 & $296 \sim 319$ \\
\hline In HANARO & 0.10 & 1.100 & $290 \sim 310$ \\
\hline
\end{tabular}

*Grid strap temperature in the plant is acquired through the inlet and outlet reactor temperatures. 
measurement uncertainty. Therefore, further study is required with high fluence and longer specimens.

\section{ACKNOWLEDGMENTS}

This work was supported by a government grant provided by the Power Generation \& Electricity Delivery Program of the Korea Institute of Energy Technology Evaluation and Planning (KETEP) and funded by the Korean Ministry of Knowledge Economy (No. R-20051-391).

\section{REFERENCES}

[ 1 ] H.R. Higgy, F.H. Hammad, "Effect of Neutron Irradiation on the Tensile Properties of Zircaloy-2 and Zircaloy-4", Vol. 44, p. 215, 1972.

[2] A. Rogerson, "Irradiation Growth in Zirconium and its Alloys", Journal of Nuclear Materials, Vol.159, p. 43, 1988.

[ 3 ] John Williams, Edward C. Darby, and David C.C. Minty, Zirconium in the Nuclear Industry : Soxth International
Symposium, ASIM STP 824, p. 376-393, 1984.

[4] J.E. Harbottle, “ The Temperature and Neutron Dose Dependence of Irradiation Growth in Zircaloy-2”, ASTMSTP-485, p. 287-299, 1970.

[ 5 ] Steven J. King, Ronald L. Kesterson, Ken H. Yueh, Robert J. Comstock, William M. Herwig, and Scott D. Ferguson, "Impact of Hydrogen on Dimensional Stability of ZIRLO Fuel Assemblies", Zirconium in the Nuclear Industry, ASTM STP 1423, p. 471, 2009.

[6] A. Seeger and U. Essman, Radiation Damage, in : Solidi (Academic Press, New York and London, 1962)

[7] H. R. Higgy and F. H. Hammad, "Effect of Neutron irradiation on the Tensile Properties of Zircaloy-2 and Zircaloy-4", Journal of Nuclear Materials, Vol 44, p. 215, 1972.

[ 8 ] E. N. Harbinson and C. J. Baroch, Journal of Materials, Vol 3, p. 107, 1968.

[9] A. Rogerson, "Irradiation Growth in Zirconium and its Alloys", Journal of Nuclear Materials, Vol 159, p. 43, 1988.

[10] A. Rogerson and R.H. Zee, Journal of Nuclear Materials, Vol 152, p. 224, 1988. 